\title{
A nutrition survey of children from one-parent families in Newcastle upon Tyne in 1970
}

\author{
BY SYLVIA J. DARKE, MOLLY M. DISSELDUFF AND G. P. TRY \\ Department of Health and Social Security, Alexander Fleming House, \\ Elephant and Castle, London SEI $6 B Y$
}

(Received 24 September 1979 - Accepted 30 May 1980)

\begin{abstract}
I. A $7 \mathrm{~d}$ total dietary record was kept in 1970 by schoolchildren from one-parent families and by a control sample matched for sex and age who were living with both parents. The children were aged, on average, I4.5 years and were from schools in Newcastle upon Tyne. Medical assessments were made within 2 weeks of the dietary study.

2. Mean daily intakes of food energy and most nutrients were significantly larger $(P<0.05)$ in the fatherless boys compared with the controls. There was no such difference between the corresponding two groups of girls. The quality of the diet, assessed as nutrients/MJ was similar in all four groups.

3. There was no evidence of undernutrition; a few children were considered to be obese. The findings in a period of relative affluence may serve as a baseline for subsequent dietary studies.
\end{abstract}

Children from families where there was no male adult living in the household were thought to constitute a possible 'at risk' group in the population. This study was made in 1970 to assess the nutritional status of a sample of such children and to compare then with a group of children of the same age from two-parent families.

\section{EXPERIMENTAL}

\section{Subjects}

Letters were sent to the parents of 2960 children aged I 4 years who attended a representative selection of schools in the city of Newcastle upon Tyne. The letters explained the purpose of the survey and asked for information about the composition of the household. The response rate was $7 \mathrm{I} \%$. Approximately one in eleven of the children were from fatherless households but no estimate was made of the length of time for which the family had been a one-parent family. From these a sample of fifty-five boys and fifty-five girls was randomly selected. The sample was then matched for sex and month of birth by a control sample drawn from children of two-parent families. Information obtained during the fieldwork led to the exclusion of seven boys and eight girls who had been incorrectly classified as fatherless, and one boy and one girl who had originally been classified as having two parents but became fatherless before fieldwork commenced. There was also some non-co-operation, and a few dietary records were unusable. As a result there was some mis-matching of the two samples (Table I).

Table I. Numbers of children who took part in the Newcastle upon Tyne study in 1970

Originally selected

After exclusion of those

incorrectly classified

Usable diet records

Medical assessment

Mean age (years)

\begin{tabular}{|c|c|}
\hline \multicolumn{2}{|c|}{ Boys } \\
\hline Fatherless & With father \\
\hline 55 & 55 \\
\hline 48 & 54 \\
\hline 39 & 47 \\
\hline 36 & 43 \\
\hline 14.5 & $14 \cdot 5$ \\
\hline
\end{tabular}

$\overbrace{\begin{array}{c}\text { Fatherless } \\ 55\end{array}}^{\text {Wirls }} \begin{array}{cc}\text { With father } \\ & \\ 47 & 54 \\ 36 & 41 \\ 33 & 37 \\ 14.5 & 14.5\end{array}$




\section{Sylvia J. Darke, Molly M. Disselduff and G. P. Try}

\section{Methods}

Trained investigators visited each household to complete a socio-economic questionnaire. The children or their mothers were asked to keep a record of all food and drink consumed, including school meals, for a period of seven consecutive days (Ministry of Health, I968; Department of Health and Social Security, 1975). A system of cumulative weighing was explained and food scales were loaned to households. Each item of food was weighed just before it was eaten and the weight of food left on the plate was noted. A record was also kept of any sweets or drinks eaten between meals. Appropriate quantity units were used for the few items which were too small to weigh so that the total net intake of each food group, food energy and certain nutrients could be calculated. Within $14 \mathrm{~d}$ of the $7 \mathrm{~d}$ dietary record period the children were examined clinically for signs of dietary deficiency. Nutritional status was also subjectively assessed as either good, fair or poor, and obese or not obese.

\section{RESULTS}

Nutrient intakes

Table 2 shows the mean daily intakes of food energy, selected nutrients and 'added sugars' (sugars, usually sucrose, which were added during food processing, cooking or at table as distinct from naturally-occurring sugars). As would be expected, the boys ate more than the girls. Fatherless boys had mean intakes of food energy and of many of the selected nutrients except fat and retinol which were significantly greater $(P<0.05)$ than the other boys. This was largely explained by the higher energy intake. There were no significant differences between the mean energy and nutrient intakes in the two groups of girls.

In general, the quality of the diet, assessed as nutrient intake/MJ was similar in all four groups. Mean calcium intakes/MJ were larger for the fatherless boys, and smaller for the fatherless girls, than for the control boys and girls although the differences were not quite statistically significant. There were, however, differences in milk consumption. Fatherless boys had a significantly higher mean daily intake of milk ( $450 \mathrm{~g}$ ) than boys with a father $(380 \mathrm{~g})$. The mean daily intakes for girls did not differ significantly (fatherless girls $240 \mathrm{~g}$, girls with father $280 \mathrm{~g}$ ).

\section{Intakes from school meals}

Some of the children were surveyed during the school term and intakes from school meals are shown in Table 3. Mean intakes conformed to the standard then required for school meals, i.e. that the meal should supply one-third of the recommended daily energy intake and rather more than one-third of the recommended daily amount of protein. (Department of Education and Science, I966). At school, as for the whole day, the fatherless boys had significantly higher mean intakes of energy than the other boys. There was little difference between the two groups of girls. The higher energy consumption of the fatherless boys was associated with a significantly greater intake $(P<0.001)$ of 'added sugars'. They ate on average $27 \mathrm{~g} / \mathrm{school}$ meal compared with $18 \mathrm{~g} / \mathrm{meal}$ consumed by the other boys whereas the mean daily intake of added sugars was approximately the same for both groups of girls. Total carbohydrate intakes were also significantly higher for the fatherless boys. These findings indicated that the fatherless boys were eating on average larger portions of the sweet course. Fatherless boys took school meals a little more frequently than boys with a father: on the average $2.8 \mathrm{~d} /$ week $v, 2.1 \mathrm{~d} /$ week, this difference was not statistically significant. The corresponding values for the girls were $2 \cdot 3$ and $2 \cdot 4 \mathrm{~d} /$ week.

\section{Medical assessment}

At the medical examination no clinical signs of dietary deficiency were seen. There were no children classified as of 'poor' nutritional status, but two boys (one fatherless) and two girls 


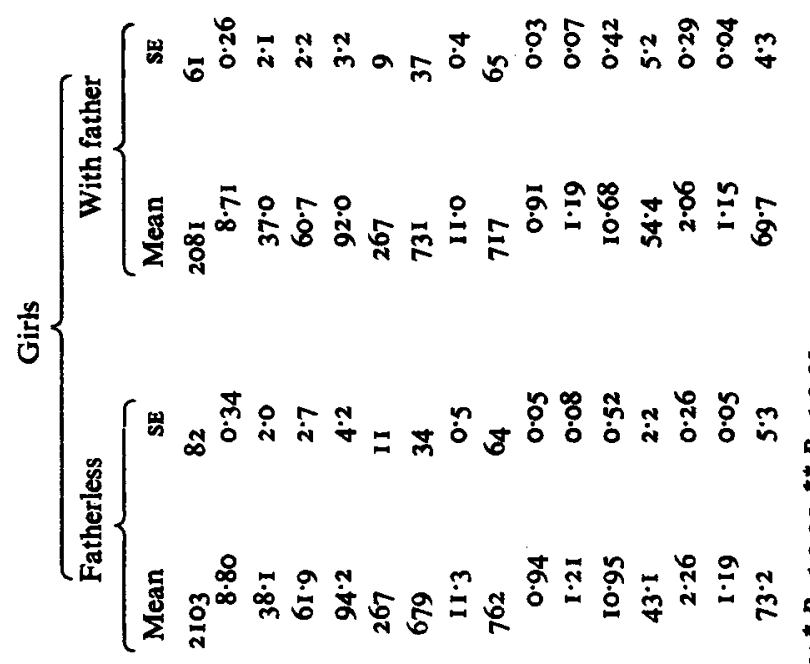

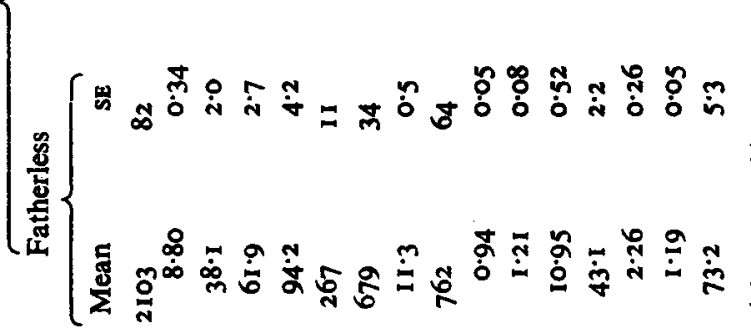

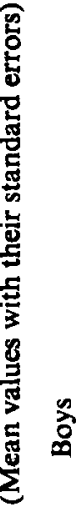

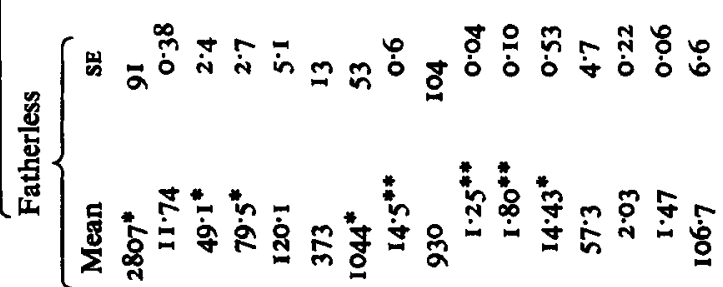

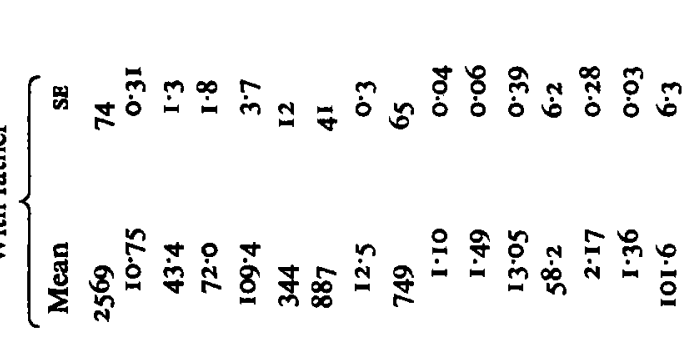

8 


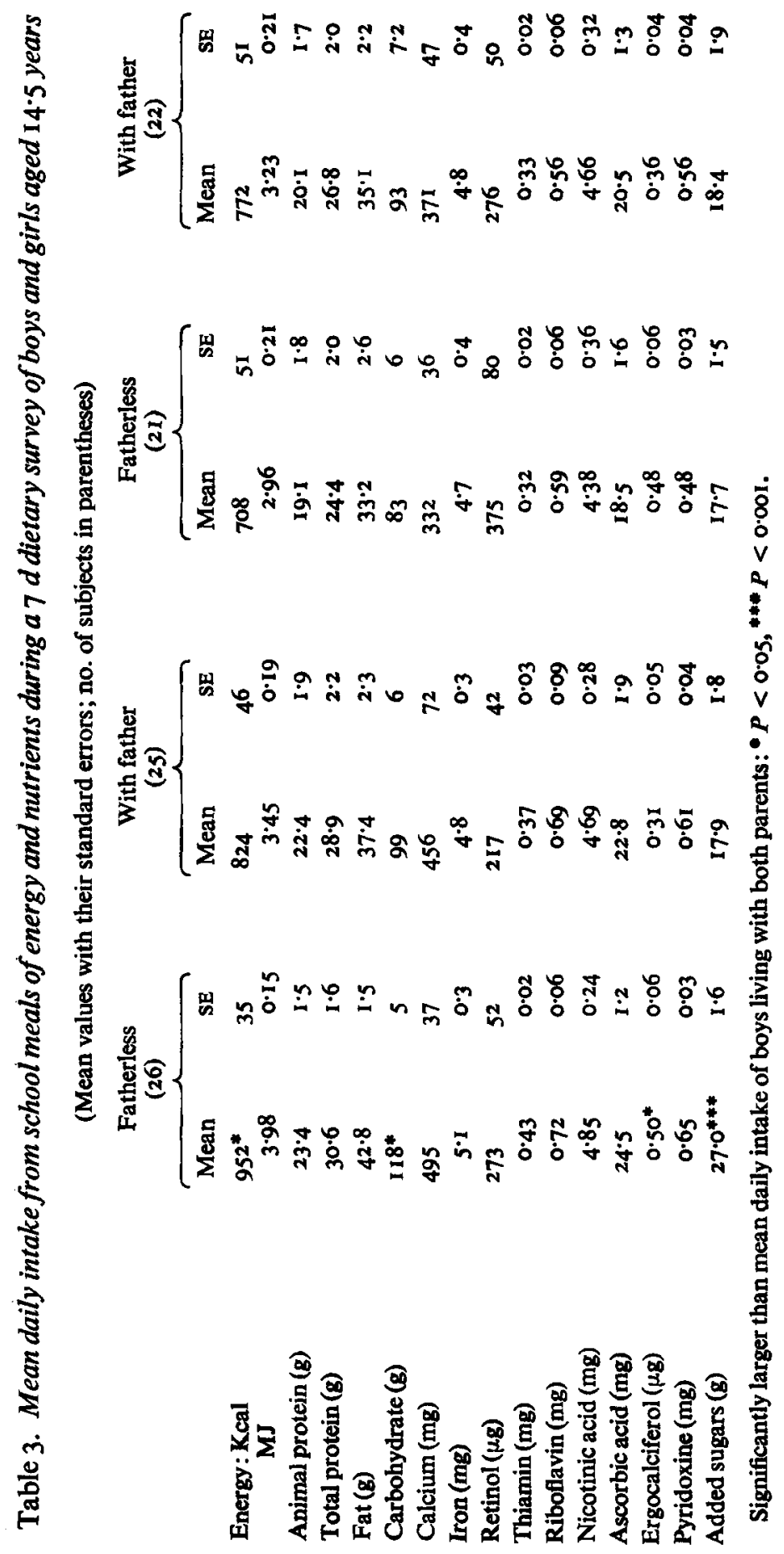


(one fatherless) were classified 'fair'. Four boys and eight girls were judged clinically to be obese (three of each were fatherless). The other 133 children who had medical examinations appeared to be of good nutritional status.

\section{DISCUSSION}

The most important findings of this study were that none of the children showed clinical signs of undernutrition, and the mean daily food energy and nutrient intakes of these fatherless children were not smaller than those of the children matched for age and sex, who were living with both parents.

In a study of Kent schoolchildren aged 8-I I and I3-I5 years Cook et al. (1973) found no difference in the energy intake of sixty-nine fatherless children compared with the other children but the fatherless children had a better-quality diet. In this study, the average intakes of the fatherless girls were no different from those of the other girls, but the mean daily intakes of food energy and of all the selected nutrients except fat and retinol, were significantly bigger for the fatherless boys compared with their controls. The quality of the diet as indicated by nutrients/MJ was similar for boys and girls from one-parent and twoparent households.

Holland et al. (1969) found that fatherless boys smoked more than other boys ( $50 \% \mathrm{v}$. $25 \%$ ) but no such difference was found for girls. It is possible that within a household fatherless boys tend to take the place of a father, have more freedom in such matters as smoking and also receive preferential treatment at meals.

The authors thank all those who co-operated in the study; in particular the dietary investigators, Dr W. B. Shaw Deputy Medical Officer of Health for Newcastle, Dr W. M. Waggott who helped with the medical examinations, and colleagues in the Department of Health and Social Security for help with the analysis of results.

\section{REFERENCES}

Cook, J., Altman, D. G., Moore, D. M. C., Topp, S. G., Holland, W. W. \& Elliott, A. (1973). Br. J. prev. Soc. Med. 27, 91 .

Department of Education and Science (1966). Circular no. 3/66. London: H.M. Stationery Office.

Department of Health and Social Security (1975). Rep. Hlth. Soc. Subj., Lond. no. Io.

Holland, W. W., Halil, T., Bennett, A. E. \& Elliott, A. (1969). Milbank Meml Fund Bull. no. 215.

Ministry of Health (1968). Rep. Publ. Hlth. Med. Subj. Lond. no. 118. 